\title{
CYLINDRICAL FLOW IN AND OVER CHANNELS OF IRREGULAR SHAPE
}

\author{
By E. M. SHOEMAKER
}

(Department of Mathematics, Simon Fraser University, Burnaby, British Columbia V5A 1S6, Canada)

\begin{abstract}
Earlier work by Nye (1965), who obtained numerical solutions for axial independent flow of a non-linear Glen material in channels of rectangular, elliptic, and parabolic cross-sections with a null-slip basal condition, is extended by using an inverse technique. Exact analytical solutions are obtained for flow in irregular-shaped channels (subject to symmetry restrictions) for both a Newtonian and an $n=3$ Glen material. The cross-sections are regulated by multi-parameters. Solutions are obtained for two types of channel: (a) those whose side walls meet the free ice surface vertically, and (b) periodic channel arrays whose basal profiles do not intersect the free ice surface, i.e. overfilled channels. Solutions for the second type have not been presented previously. The solutions for the $n=3$ Glen material employ a small parameter which limits the geometry variation to perturbations on semicircular or uniform-depth channels. Basal slip conditions can be incorporated although results are not presented here.
\end{abstract}

RÉsumé. Fluage cylindrique dans et sur des chenaux de forme irrégulière. Le premier travail de Nye (1965), qui obtint des solutions numériques pour des écoulements indépendants de la direction axiale d'un corps de Glen non linéaire dans des chenaux de section droite rectangulaires, elliptiques et paraboliques sans glissement sur le lit, est étendu à l'aide d'une technique d'inversion. Des solutions analytiques exactes sont obtenues pour l'écoulement dans des chenaux de formes irrégulières (soumises néanmoins aux règles de la symétrie à la fois pour un corps newtonien et un corps de Glen où $n=3$. Les sections droites sont déterminées par des paramètres multiples. Les solutions sont obtenues pour deux sortes de chenaux (a) ceux pour qui la surface libre coupe normalement la rive, (b) ceux périodiques pour lesquels le profil du lit ne coupe pas la

\section{INTRODUCTION}

Nye (1965) examined the steady rectilinear flow of a Glen material in channels of prescribed cross-section: rectangular, elliptic, and parabolic, under a zero-velocity basal condition. The analysis consisted necessarily of a fully numerical solution of the partial differential equations. Nye also presented two analytical solutions for flow in an infinitely wide channel of uniform depth and in a semi-circular filled channel. He also presented an analytical solution due to W. Chester (private communication between Chester and Nye) for a slightly elliptic channel obtained by a standard perturbation of the solution for a semicircular channel. Finally, he noted that a standard perturbation could not be performed on the solution for the infinitely wide channel of uniform depth.

The emphasis here will be on analytical solutions because such solutions are more adaptable for qualitative studies. Although we shall again assume a zero-velocity basal condition, the techniques exhibited can be applied to other basal conditions such as a Weertman (1957, 1964) sliding law. There are two reasons why we restrict surface libre, c'est-à-dire des chenaux noyés. Des solutions pour ce second genre n'ont jamais été présentées auparavant. Les solutions pour un corps de Glen avec $n=3$, utilise un petit paramètre qui limite les variations géométriques aux perturbations des chenaux semi-circulaires ou d'épaisseur uniforme. Les conditions de glissement à la base peuvent être introduites bien que ces résultats ne soient pas présentés.

ZUSAMmenfassung. Zylindrisches Fliessen in und über Kanälen von unregelmässiger Gestalt. Frühere Arbeiten von Nye (1965), der numerische Lösungen für das achsunabhängige Fliessen eines nichtlinearen Glen'schen Materials in Kanälen mit rechteckigen, elliptischen und parabolischen Querschnitten bei Fehlen von Gleiten am Untergrund erhielt, werden durch Anwendung einter inversen Technik erweitert. Exakte analytische Lösungen ergeben sich für den Fluss in unregelmässig geformten Kanälen (unter gewissen Symmetrie-Bedingungen) sowohl für ein Newton'sches Material sowie solches mit einem Glen-Exponenten $n=3$. Die Querschnitte werden durch eine Schar von Parametern erfasst. Die Lösungen gelten für zwei Kanaltypen: (a) solche, deren Seitenwände senkrecht auf die freie Eisoberfläche treffen, und (b) periodische Kanalanordnungen, deren Grundprofile die freie Eisoberfläche nicht schneiden, d.h. überlaufende Kanäle. Lösungen für den zweiten Typ wurden bisher noch nicht angegeben. Die Lösungen für Material mit dem Glen-Exponenten $n=3$ verwenden einen kleinen Parameter, der die geometrischen Variationen auf Abweichungen von halbkreisförmigen Kanälen oder solchen mit gleichförmiger Tiefe beschränkt. Bedingungen für das Gleiten am Untergrund können eingeführt werden, doch werden entsprechende Ergebnisse nicht vorgelegt. the study to the non-sliding case. First, a direct comparison with Nye's work is then possible. Second, the whole subject of sliding laws is currently at issue.

For brevity, Nye's assumptions, notation, coordinate system, and sign conventions (his fig. la and b) are used throughout. We are concerned with the steady cylindrical flow of a homogeneous, isotropic Glen material. In addition, we assume that the $x y$ plane is a plane of symmetry. (The $x$-axis lies on the ice surface and points down-slope with the $y$-axis into the bed through the thalweg.)

The equilibrium equations reduce to the single equation

$$
\frac{\partial \tau_{x y}}{\partial y}+\frac{\partial \tau_{x z}}{\partial z}=-\rho g \sin \alpha
$$

where $\alpha$ is the bed slope. Glen's flow law reduces to

$$
\frac{\partial u}{\partial y}=A \tau^{n-1} \tau_{x y} \frac{\partial u}{\partial z}=A T^{n-1} T_{x z}
$$


where $\tau \equiv\left(\tau_{x y}{ }^{2}+T_{x z}{ }^{2}\right)^{1 / 2}$. We shall consider two cases:

$\mathrm{n}=1$, a Newtonian material, and $\mathrm{n}=3$, which is a popular but not universal choice to represent ice. Under assumptions invoked here, $\mathrm{A}$ is a constant.

A solution involves finding the two stress components $\boldsymbol{T}_{\mathrm{xy}}, \boldsymbol{T}_{\mathrm{xz}}$ and longitudinal velocity $\mathrm{u}$ which satisfy (1) and (2) along with certain boundary conditions. The boundary conditions consist of the free surface condition

$$
\tau_{\mathrm{xy}}(0, \mathrm{z})=0
$$

and the null-velocity condition $u=0$ on a basal profile as yet to be determined. In addition, symmetry implies that

$$
\tau_{\mathrm{xz}}(\mathrm{y}, 0)=0 .
$$

In cases of flows periodic in $z$ condition, (4) is replaced by

$$
\tau_{\mathrm{Xz}}(\mathrm{y}, \pm \mathrm{ml})=0, \quad \mathrm{~m}=0,1,2, \ldots .
$$

\section{ANALYSIS FOR A NEWTONIAN MATERIAL}

Most creep data for ice apply above 1 bar. At this high stress range there is considerable variation in values of $n$ measured in the laboratory and calculated from field measurements. (see, for example, Paterson (1981).) However, there is no ambiguity in the conclusion that $\mathrm{n}>1$, i.e. the behaviour is non-Newtonian.

Laboratory tests carried out at small total creep strains and at low stresses show $\mathrm{n} \approx 1$, (see, e.g. Landauer, 1955; Jellinek and Brill, 1956; Bromer and Kingery, 1968; Mellor and Testa, 1969; and Colbeck and Evans, 1973). However, Weertman (1973) offers the explanation that, because the total creep strains are so small in these experiments, it is unlikely that the dislocation density has reached the steady-state value. Values of $n$ calculated from field observation at low stresses vary, but in general exceed unity. Shreve and Sharp (1970) from analysis of bore-hole data, Nye (1953) from tunnel closure, and Thomas (1971) and Dorrer (1971) from ice shelf spreading support a value $\mathrm{n} \approx 3$. On the other hand, Gerrard and others (1952) from bore-hole data as reexamined by Nye (1957) indicates a lower value $\mathrm{n} \approx 2$. (This is my calculation from Nye's figure 6 , Curve $T_{1}$, taken at the base of the glacier.)

The situation involving the measurement of the index $\mathrm{n}$ at low stresses is further clouded by the fact that there are no field measurements at stresses as low as 0.25 bar. In addition, as pointed out by Paterson (1981) and by Morland and Shoemaker (1982) for the case of ice shelves, there are serious difficulties involved in calculating $\mathrm{n}$ from any field data. It would seem that until this ambiguity is removed in favour of a value of $n$ much greater than one there is justification for treating the linear case here.

Consider the following class of functions as prospective velocity field in Equation (2):

$$
\begin{gathered}
u=\frac{a A K}{2}\left[1-\left[\frac{y}{a}\right]^{2}-\sum_{i=1}^{m_{1}} B_{i} \cos \frac{i z}{b} \cosh \frac{i y}{b}-\right. \\
\left.-\sum_{i=1}^{m_{2}} C_{i} \cos \frac{i y}{b} \cosh \frac{i z}{b}\right] .
\end{gathered}
$$

Here, $\mathrm{K}=\rho g a \sin \alpha$ is a characteristic stress as used by Nye, the basal stress for an infinitely wide channel of depth a. Coefficient $b$ is a horizontal length scale. Coefficients $B_{i}$ and $C_{i}$ are arbitrary at this stage. For the special case $B_{i}=C_{i}=0$, all $i$, Equation (5) reduces to the velocity field for an infinitely wide channel of depth a (Nye, 1965).

Flow Equations (2) with $\mathrm{n}=1$ determine the associated stress components

$$
\begin{aligned}
\tau_{x y} & =\frac{a K}{2}\left[-\frac{2 y}{a^{2}}-\frac{1}{b} \sum_{i=1}^{m_{1}} i B_{i} \cos \frac{i z}{b} \sinh \frac{i y}{b}+\right. \\
& \left.+\frac{1}{b} \sum_{i=1}^{m_{2}} i C_{i} \sin \frac{i y}{b} \cosh \frac{i z}{b}\right], \\
\tau_{x z} & =\frac{a K}{2}\left[\frac{1}{b} \sum_{i=1}^{m} i B_{i} \sin \frac{i z}{z} \cosh \frac{i y}{b}-\right. \\
& -\frac{1}{b} \sum_{i=1}^{m} i_{i} \cos \frac{i y}{b} \sinh \frac{i z}{b} .
\end{aligned}
$$

Equilibrium Equation (1) is satisfied identically by Equations (6), as are the boundary conditions (3) and (4).

Rather than attempting to choose coefficients so that the null velocity condition is satisfied on a predetermined basal profile, it is easier and far more flexible to adopt an inverse approach, thus assigning coefficients and determining the resultant null velocity profile. To this end we shall examine two special cases which will prove to be sufficiently general to illustrate the possibilities of the method.

\section{BASAL PROFILES INTERSECTING $z$-AXIS}

If $\mathrm{C}_{1}$ is the only non-zero coefficient in Equation (5) the null-velocity profile is determined as the solution to

$$
C_{1} \cos \frac{y}{b} \cosh \frac{z}{b}+\left[\frac{y}{a}\right]^{2}=1 .
$$

With the characteristic length a fixed, Equation (7) contains two parameters. It is a simple numerical task to determine the ranges of $b$ and $C_{1}$ which place the thalweg at $\mathrm{z}=0$ as required.

Figure 1 graphs the right half of six basal profiles on axes $y / a, z / a$; three intersect the $y / a$ axis at 0.3 and

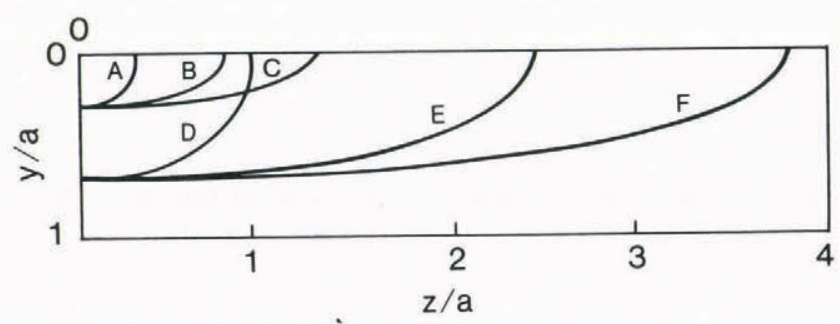

Fig. 1. The right half of six basal profiles corresponding to a Newtonian material and null-velocity basal condition. Parameter values are:

Curve $A: b=a, C_{1}=0.6668$ :

Curve $B: b=2 a, C_{1}=0.5429$;

Curve $C: b=3 a, C_{1}=0.5242$

Curve $D: b=a, C_{1}=0.95254$;

Curve $E: b=2 a, C_{1}=0.92033$;

Curve $F: b=3 a, C_{1}=0.9146$.

three at 0.7 . The profiles resemble ellipses. Our primary interest is in shape modification, not scale. Scale can always be adjusted by varying the constant a. With scale removed from consideration, two parameters remain for shape modification and this is reduced to one if the width/depth ratio of the channel is specified.

To illustrate the flexibility of a one-parameter modification to shape with a fixed width/depth ratio we consider basal profile families which have the same intercepts on $y / y_{i}, z / y_{i}$ axes, where $y_{i}$ is the $y$ intercept of any curve. Let $c=z_{i} / y_{i}$ be the fixed ratio of the 
intercepts. Substituting the intercepts $\left(0, c y_{i}\right)$ and $\left(y_{i}, 0\right)$ into Equation (7) gives

$$
\begin{aligned}
& \mathrm{C}_{1}=\operatorname{sech}\left(\mathrm{cy}_{\mathrm{i}} / \mathrm{b}\right), \\
& \cosh \left(\mathrm{cy}_{\mathrm{i}} / \mathrm{b}\right)=\cos \left(\mathrm{y}_{\mathrm{i}} / \mathrm{b}\right) /\left(1-\left(\mathrm{y}_{\mathrm{i}} / \mathrm{a}\right)^{2}\right) .
\end{aligned}
$$

With $\mathrm{a}=1$, and $\mathrm{b}$ and $\mathrm{c}$ assigned, $\mathrm{y}_{\mathrm{i}}$ is determined from Equation (9) and $C_{1}$ from Equation (8). The basal profiles are then found from Equation (7) as before.

Figure 2 illustrates profiles corresponding to $\mathrm{c}=1$ and $\mathrm{c}=2$. It is clear that the single parameter which

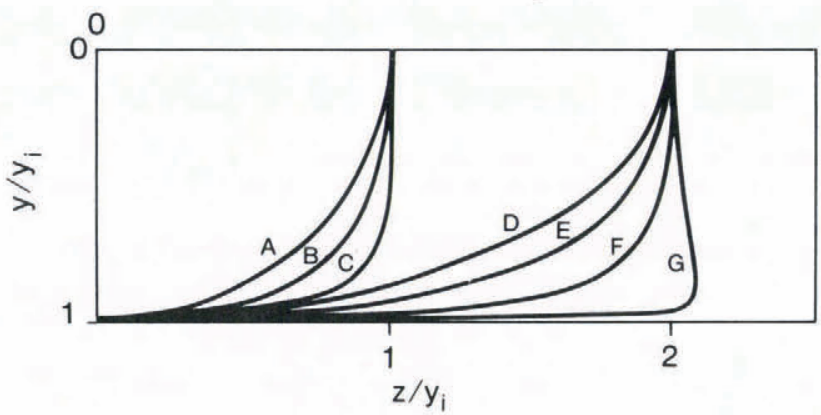

Fig. 2. The right half of seven basal profiles plotted on $y / y_{i}, 2 / y_{i}$ axes. Parameter values are:

Curve $A: \quad b=0.95 a, C_{1}=0.9024$ :

Curve $B: \quad b=0.8 a, C_{1}=0.6381$

Curve $C: \quad b=0.7 a, C_{1}=0.4855$;

Curve $D: \quad b=1.55, C_{1}=0.9555$

Curve $E: \quad b=1.5 a, C_{1}=0.8859$

Curve $F: \quad b=a C_{1}=0.3271$;

Curve $G: \quad b=0.75 a, C_{1}=0.1454$

governs shape affords considerable variation. Velocity and stress results are not illustrated; these are easily obtained from Equations (5) and (6) and are qualitatively similar to Nye's results.

\section{BASAL PROFILES NOT INTERSECTING $z$-AXIS}

If $B_{1}$ is the only non-zero coefficient in Equation (5), the null-velocity profile is determined as the solution to

$$
B_{1} \cos \frac{z}{b} \cosh \frac{y}{b}+\left[\frac{y}{a}\right]^{2}=1
$$

Profiles of this class are periodic in $z$ and may not intersect the $\mathrm{z}$-axis. In that event exact solutions are

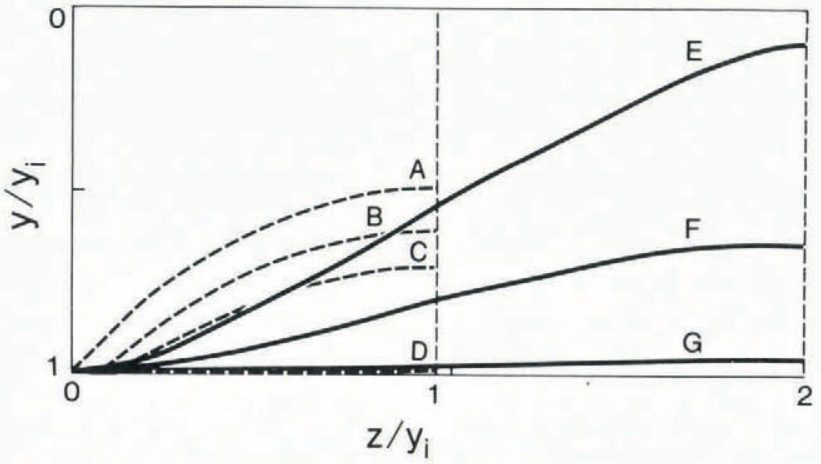

Fig. 3. The right half of seven periodic basal profiles plotted on $y / y_{i}, z / y_{i}$ coordinates. The ice surface corresponds to the top of the box. Parameter values are.

Curve $A: \quad b / a=0.53, B_{1}=-0.1529$

Curve $B: \quad b / a=0.45, B_{1}=-0.0861$

Curve $C: \quad b / a=0.40, B_{1}=-0.0500$

Curve $D: \quad b / a=0.32, B_{1}=-0.000011852$

Curve $E: \quad b / a=1.175, B_{1}=-0.9591$;

Curve $F: \quad b / a=0.8, B_{1}=-0.2308$ :

Curve $G: \quad b / a=0.65, B_{1}=-0.016929$. provided for Newtonian flow in overfilled channels (an ice sheet flowing over a periodic array of cylindrical channels in the direction of the cylindrical axes). Since this problem has not been previously considered, we illustrate some details of the velocity and stress fields.

Figure 3 graphs families of half wavelength basal profiles plotted on axes $y / y_{i}, z / y_{i}-$ similar to Figure 2 . Profiles are shown for $c=1$ and $c=2$ where $c$ is the ratio of the half wavelength to ice depth at the thalweg. With $c$ and b/a given, the dimensionless half wavelength $z_{i} / a$ is found from the condition $\cos z_{i} / b=1$ or

$$
\mathrm{z}_{\mathrm{i}} / \mathrm{a}=\mathrm{b} \pi / \mathrm{a},
$$

The dimensionless intercept $y_{i} / a$ is then given by

$$
\mathrm{y}_{\mathrm{i}} / \mathrm{a}=\mathrm{z}_{\mathrm{i}} / \mathrm{ca}=\mathrm{b}_{\pi} / \mathrm{ca} .
$$

Finally, $B_{1}$ is found from Equation (10) which gives

$$
\mathrm{B}_{1} \cosh \mathrm{y}_{\mathrm{i}} / \mathrm{b}+\left(\mathrm{y}_{\mathrm{i}} / \mathrm{a}\right)^{2}=1 \text {. }
$$

Note that all basal profiles are smooth and intersect the $\mathrm{y} / \mathrm{y}_{\mathrm{i}}$ axis orthogonally. Thus, curve $\mathrm{A}$ approximates a $V$-shaped profile but the bottom is actually rounded at the thalweg.

Figure 4 illustrates dimensionless velocity profiles and dimensionless boundary stresses corresponding to curve $\mathrm{E}$ of Figure 3. Dimensionless velocity is defined by

$$
\mathrm{U}=\mathrm{u} /\left[\frac{\mathrm{aAK}}{2}\right]
$$

where $a A K / 2$ is the surface velocity in an infinitely wide channel of uniform depth a for a linear material. In terms of dimensionless variables $Y=y / y_{i}, Z=z / y_{i}$ where $y_{i}$ is given by Equation (12)

$$
\mathrm{U}=1-\left(\frac{\pi \mathrm{b}}{\mathrm{ca}} \mathrm{Y}\right)^{2}-\mathrm{B}_{1} \cos \left(\frac{\pi \mathrm{Z}}{\mathrm{c}}\right) \cosh \left(\frac{n \mathrm{Y}}{\mathrm{c}}\right) .
$$

In Figure 4 , since $\mathrm{b} / \mathrm{a}=1.175$ and $\mathrm{c}=2$ the channel depth at the thalweg is $y_{\mathrm{i}} / \mathrm{a}=1.85$ from Equation (12). Thus, the maximum channel depth is greater than a which explains why values of $U$ exceed unity.

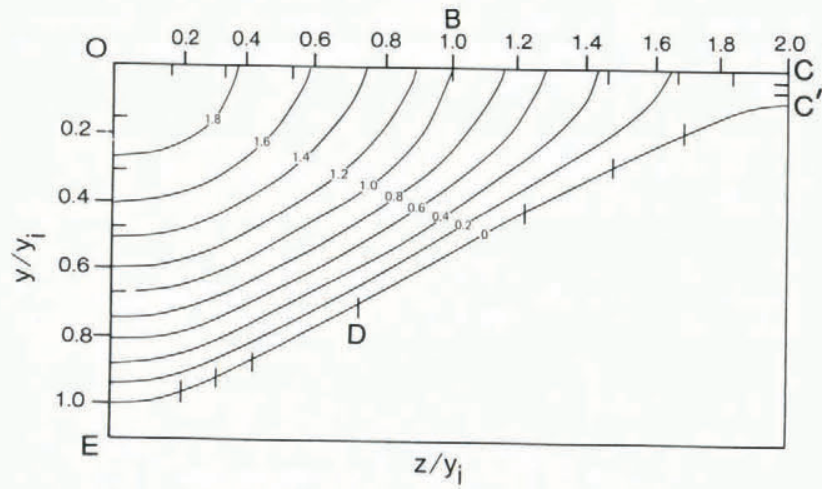

Fig. 4. Dimensionless velocity profiles $U$ at intervals of 0.2 and dimensionless boundary stresses $T$ for the case $c=2 b / a=1.175, B_{1}=-0.9591$. The inner boundary tick marks indicate equal stress increments over intervals $O B, B C, C C^{\prime} ; C^{\prime} D, D E$, and $E O$ on which stress varies monotonically. (The increments are not the same for all intervals.) Key stresses are:

O: $T=0.0, \quad B: T=0.408, \quad C: T=0.0, C^{\prime}: T=0.230$ $D: T=1.23, E: T=0.906$

Dimensionless effective stress is defined by

$$
\mathrm{T}=\sqrt{\tau_{\mathrm{xy}}^{2}+\tau_{\mathrm{xz}}^{2}} / \mathrm{K} .
$$

In dimensionless variables $(\mathrm{Y}, \mathrm{Z})$ this becomes 


$$
\begin{aligned}
T & =\left[\left[\frac{\pi b}{c a} Y+\frac{B_{1}}{2} \frac{a}{b} \cos \frac{\pi Z}{c} \sinh \frac{\pi Y}{c}\right]^{2}+\right. \\
& \left.+\left[\frac{a B_{1}}{2 b} \sin \frac{\pi Z}{c} \cosh \frac{\pi Y}{c}\right]^{2}\right]^{1 / 2}
\end{aligned}
$$

where $\tau_{x y}$ and $T_{x z}$ are computed from Equation (6).

Because $T$ is proportional to grad $U$ for a linear material one can visualize the profiles of $T$ from the boundary values of $T$ and profiles of $U$ illustrated. The boundary stresses are given by the tic marks on the inner boundary which are spaced at equal increments of $T$ over arcs $\mathrm{OB}, \mathrm{BC}, \mathrm{CC}^{\prime}, \mathrm{C}^{\prime} \mathrm{D}, \mathrm{DE}$, and $\mathrm{EO}$ on which stress varies monotonically. The increments are not the same for all intervals. The key stresses are: $\mathrm{O}: \mathrm{T}=0.0$, B: $T=0.408, C: T=0.0, C^{\prime}: T=0.230, \quad D: T=1.23$, $E: T=0.906$. Thus, $T$ has an overall maximum at point $D$ and a relative maximum at point $B$. The boundary stress on $\mathrm{OBC}$ is sinusoidal as can be seen from Equation (15'). The fact that $T=0$ at point $C$ follows from the symmetry of the periodic channel array. The stress would not vanish at $C$ nor be sinusoidal on the free surface for an isolated valley.

The Nye shape factor is easily computed. Thus, the dimensionless shear stress at the thalweg, assuming plane flow, is equal to the dimensionless ice depth, or 1.85 . The actual dimensionless stress is 0.906 . Thus, the Nye shape factor value is $f=0.49$.

\section{PROFILES FOR $n=3$ NOT INTERSECTING $z$-AXIS}

For a non-linear material it is difficult to produce an interesting class of velocity fields which is associated with an equilibrium stress field through Glen's flow law. Taking a new approach we consider the equilibrium stress field

$$
\begin{aligned}
& \tau_{x y}=-\frac{K y}{a}-\frac{\epsilon K}{a^{2}}\left(\int_{0}^{y} \xi f^{\prime}(\xi) d \xi\right) \cos \frac{z}{b}, \\
& \tau_{x z}=\frac{\epsilon K \text { by }}{a^{2}} f^{\prime}(y) \sin \frac{z}{b}
\end{aligned}
$$

where $b / a$ and $\epsilon$ are parameters and unknown function $f$ must satisfy the condition that $f$ ' be bounded. Equations (16) are substituted into Glen's flow law (2) with $\mathrm{n}=3$. This gives

$$
\begin{gathered}
\frac{\partial u}{\partial y}=A\left\{\left[\frac{K y}{a}+\frac{\epsilon K}{a^{2}} \int_{0}^{y} \xi f^{\prime}(\xi) \cos \frac{z}{b}\right]^{2}+\right. \\
\left.+\left[\epsilon K \frac{b y}{a^{2}} f^{\prime}(y) \sin \frac{z}{b}\right]^{2}\right\}\left[-\frac{K y}{a}-\frac{\epsilon K}{a^{2}} \int_{0}^{y} \xi f^{\prime}(\xi) d \xi \cdot \cos \frac{z}{b}\right], \\
\left.+\left[\frac{\frac{\partial u}{\partial z} b y}{a^{2}} f^{\prime}(y) \sin \frac{z}{b}\right]^{2}\right\}\left[\frac{\epsilon \frac{K}{a} b y}{a^{2}} f^{\prime}(y) \sin \frac{z K}{b}\right] .
\end{gathered}
$$

Equations (17) thus result in expansions in powers of $\epsilon$ out to $\epsilon^{3}$. Provided conditions can be established such that the $\epsilon^{2}$ and $\epsilon^{3}$ terms are uniformly dominated by the $\epsilon^{0}$ and $\epsilon^{1}$ terms (better yet, that the $\epsilon^{2}$ and $\epsilon^{3}$ terms are also uniformly dominated by the $\epsilon^{1}$ term), for suitably small $\epsilon$ the $\epsilon^{2}$ and $\epsilon^{3}$ terms may be neglected. (These conditions will be considered later.) Equations (17) may then be integrated, yielding a velocity field which is associated with the equilibrium stress field through the flow law only out to the first order $\epsilon$ term.
The velocity field resulting from this procedure is

$u=\frac{A K^{3}}{4} a\left(1-\frac{y^{4}}{a^{4}}\right]-A \in K^{3}\left[\frac{y}{a}\right]^{2}\left[\frac{b}{a}\right]^{2} y f^{\prime}(y) \cos \frac{z}{b}$.

The constant of integration was determined by the condition that for $\epsilon=0$ the velocity be that of an $\mathrm{n}=3$ Glen material flowing in a uniform channel of depth a.

The procedure also produces a differential equation for the determination of $f(y)$ in Equations (16) and (18). Thus,

$$
y f^{\prime \prime} \prime+4 f^{\prime \prime}-\frac{3 y f^{\prime}}{b^{2}}=0 .
$$

Letting $\mathrm{f}^{\prime}=\mathrm{g}$ gives $\mathrm{a}$ form of the modified Bessel equation which has the regular solution

$$
f^{\prime}(y)=C_{1}\left[\sqrt{\frac{3}{y}} \cosh \left(\sqrt{\frac{3}{b}}\right)-\sinh \left(\sqrt{\frac{3}{b}}\right)\right] / y^{3} .
$$

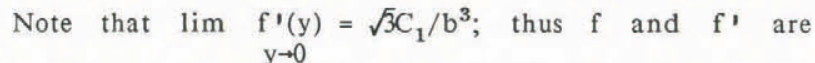
bounded. Moreover, from Equation (16b) $\tau_{\mathrm{xz}}(0, \mathrm{z})=0$ which was not a required condition. The boundary condition $\tau_{\mathrm{xz}}(\mathrm{y}, 0)=0$ is satisfied by Equation (16b) while the other boundary condition $T_{x y}(0, z)=0$ is satisfied by Equation (16a).

The quantity $\int_{0}^{y} \xi f^{\prime}(s) d \xi$, necessary for determining

$\tau_{x y}$ in Equation (16a), is found by integration using (20). This gives

$$
\int_{0}^{y} \xi f^{\prime}(\xi) d \xi=\frac{C_{1}}{y}\left[\sinh \left(\frac{\sqrt{3} y}{b}\right)\right],
$$

The constant $\mathrm{C}_{1}$ is determined by the condition that for $|\epsilon|=1$ the $\epsilon^{0^{1}}$ terms in Equations (16a and b) are just sufficient to dominate the $\epsilon^{1}$ terms throughout the flow field. It is fairly easy to show that

$$
\begin{aligned}
& C_{1}=\operatorname{Min}\left[\frac{a\left(y_{i}\right)^{2}}{\left[\sinh \left[\frac{\sqrt{3} y_{i}}{b}\right]-\frac{\sqrt{3} y_{i}}{b}\right]},\right. \\
& \left.\frac{\frac{a}{b}\left(y_{i}\right)^{3}}{\left[\sqrt{\frac{3 y_{i}}{b}} \cosh \left[\frac{\sqrt{3} y_{i}}{b}\right]-\sinh \left[\sqrt{\frac{3}{b}}\right]\right]}\right]
\end{aligned}
$$

Here $y_{i}$ is the $y$-intercept of the zero-velocity basal profile which is yet to be determined. With $C_{1}, y_{i} / a$, $\mathrm{b} / \mathrm{a}$, and $\epsilon$ given, the stress and velocity fields are known. The analysis is valid for $|\epsilon|$ small compared with unity but because the bounding procedure leading to Equation (22) was fairly crude it is expected that the useful range of $|\epsilon|$ will be somewhat larger.

We illustrate results in Figure 5 for fixed aspect ratio $\mathrm{c}$ defined as previously for the Newtonian material leading to Figure 3 . With $\mathrm{c}$ prescribed, the intercepts $\mathrm{z}_{\mathrm{i}} / \mathrm{a}$ and $\mathrm{y}_{\mathrm{i}} / \mathrm{a}$ are again given by Equations (11) and (12), respectively. Substituting the intercept $\left(y_{i}, 0\right)$ into Equation (18) with $u=0$ and solving for $\epsilon$ results in 


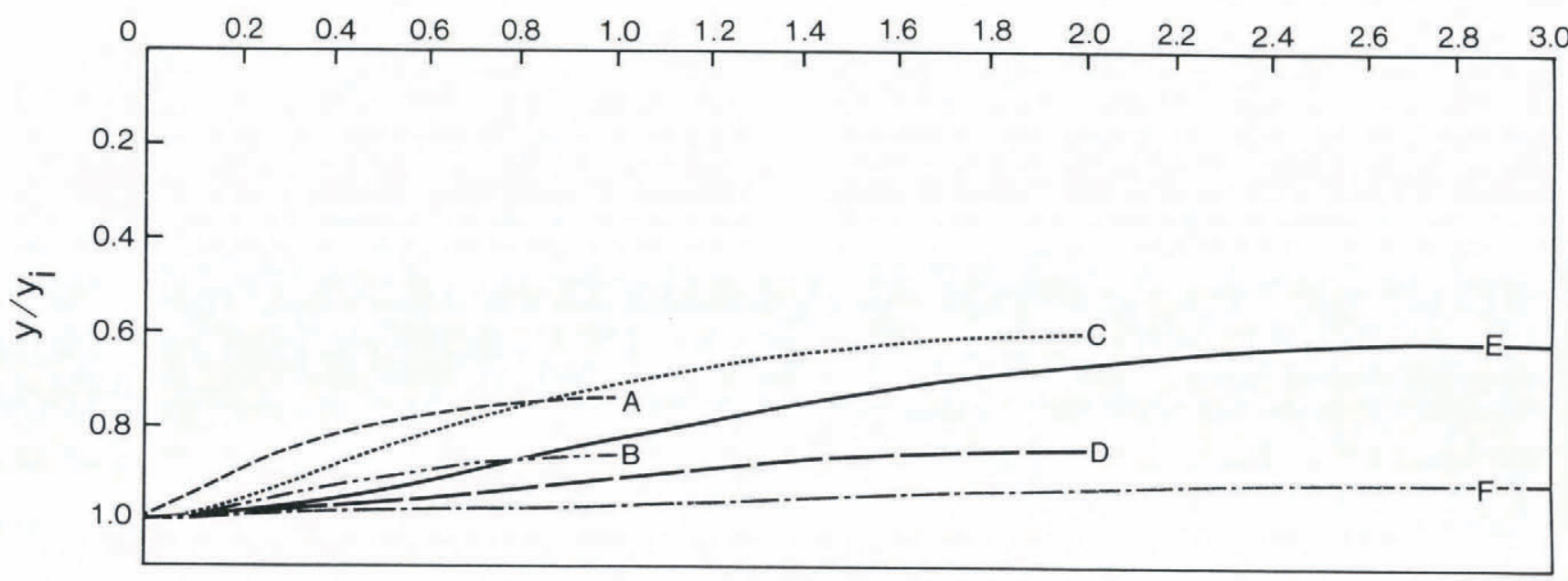

$\mathrm{z} / \mathrm{y}_{\mathrm{i}}$

Fig. 5. The right half of six periodic basal profiles for an $n=3$ Glen material. Parameters are:

Curve $A: b / a=0.4, \epsilon=-0.470$;

Curve $B: b / a=0.35, \epsilon=-0.248$

Curve $C:$ b $/ a=0.9, \epsilon=-0.294$;

Curve D: $b / a=0.7, \epsilon=-0.124$;

Curve $E: b / a=1.3, \epsilon=-0.186$;

Curve $F: b / a=1.0, \epsilon=-0.441$.

$$
\epsilon=\frac{a^{3}\left[1-\left[\frac{\pi b}{c a}\right]^{4}\right]}{4 C_{1}\left(\frac{b}{a}\right]^{2}\left[\frac{\sqrt{3} \pi}{c} \cosh \left[\frac{\sqrt{3} \pi}{c}\right]-\sinh \left[\frac{\sqrt{3} \pi}{c}\right]\right]} .
$$

At this stage, with the input parameters $c$ and $b / a$ prescribed and $z_{\mathrm{i}} / \mathrm{a}, \mathrm{y}_{\mathrm{i}} / \mathrm{a}$ determined from Equations (11) and (12), $C_{1}$ is found from Equation (22), $\epsilon$ from

Equation (23), $f^{\prime}$ from Equation (20) and $\int_{0}^{y} \xi f^{\prime}(\xi) d \xi$ from

Equation (21). Velocity is then given by Equation (18) and the stress components by Equation (16).

It is evident from Equations (16) and (18), noting that $f^{\prime}$ ' is bounded, that the perturbation on stress and velocity is not felt at the free surface $y=0$. This property is built into the general expansions (17) for $\partial u / \partial y$ and $\partial u / \partial z$ before truncation; thus, both $\partial u / \partial y$ and $\partial u / \partial z$ approach zero to order $y^{3}$ at $y=0$. This behaviour is appropriate if the basal profile is a perturbation on a horizontal base.

Note that with $C_{1}$ given by Equation (22), uniform domination of the $\epsilon^{1}$ terms by the $\epsilon^{0}$ terms is assured for $|\epsilon| \leqslant 1$. However, there is no assurance of a similar uniform domination of the $\epsilon^{2}$ and $\epsilon^{3}$ terms. A practical numerical measure of this domination will be discussed later.

Again, defining a dimensionless velocity by $\mathrm{U}=4 \mathrm{u} / \mathrm{Ak}^{3} \mathrm{a}$ where $\mathrm{AK}^{3} \mathrm{a}$ is the free-surface velocity in a channel of depth a and using dimensionless variables
$Y=y / y_{i}, \quad Z=z / y_{i}, \quad$ the dimensionless velocity field from Equations (18) and (20) is

$$
\begin{aligned}
U & =\left[1-\left[\frac{\pi}{c} \frac{b}{a} Y\right]^{4}\right]- \\
& -\frac{4 C_{1} \epsilon(b / a)^{2}}{a^{3}}\left[\frac{\sqrt{3} \pi}{c} Y \cosh \left(\frac{\sqrt{3} \pi Y}{c}\right)-\right. \\
& \left.-\sinh \left[\frac{\sqrt{3} \pi Y}{c}\right)\right] \cos \left(\frac{\pi Z}{c}\right) .
\end{aligned}
$$

(Note that $C_{1}$, from Equation (22), has the dimension [length $]^{3}$ ).

Figure 5 graphs the right half of a range of zero-velocity basal profiles determined for fixed $c$ and $\mathrm{b} / \mathrm{a}$ with $\epsilon$ and $\mathrm{C}_{1}$ determined by the previously outlined procedures. The profiles are found by setting $U=0$ in Equation (24). The results indicate that $|\in|$ increases rapidly as c decreases. Also, the cusp-line behaviour at the $y$-intercept, noted previously for the $\mathrm{n}=1$ material in Figure 3, again appears for $\mathrm{c}=1$ as $|\in|$ increases. For $c=2$ and 3 deep valley profiles (not illustrated) can be produced corresponding to the range $|\epsilon|<0.5$. Solutions for such cases should be useful for approximating Nye shape factors.

The dimensionless effective stress $\mathrm{T}$ defined by Equation (15) becomes

$$
\begin{aligned}
& T=\left\{\left[\frac{\pi}{c} \frac{b}{a} Y+\frac{\epsilon C_{1}}{\pi a} \frac{a}{3} \frac{a}{b} \frac{1}{Y}\left[\sinh \left[\sqrt{\frac{3}{\pi} \pi} \frac{Y}{c}\right]-\left[\frac{\sqrt{3} \pi Y}{c}\right]\right) \cos \frac{\pi Z}{c}\right]^{2}+\right. \\
& \left.+\left[\frac{\epsilon C_{1} c^{2}}{a^{3} n^{2}} \frac{a}{b} \frac{1}{Y^{2}}\left[\sqrt{\frac{3}{\pi} \mathrm{Y}} \frac{\cosh }{\mathrm{c}}\left[\sqrt{\frac{3}{\pi} \pi \mathrm{Y}}\right]-\left[\sqrt{\frac{3}{\mathrm{c}} \pi \mathrm{Y}} \mathrm{c}\right)\right] \sin \frac{\pi \mathrm{Z}}{\mathrm{c}}\right]^{2}\right\}^{1 / 2} .
\end{aligned}
$$


Because stresses and velocities are associated through the flow law only to the first power of $\epsilon$, relative errors in the velocity-stress relation of order $\epsilon^{2}$ are present in Equations (24) and (25). To remove this undesirable feature of the solution we can, alternatively, regard Equation (24) as a given velocity field. Stresses can then be derived by inverting Glen's flow law, Equation (2). This results in the associated stress field
Figure 6 illustrates profiles of $U$ and boundary values of $\mathrm{T}^{\mathrm{a}}$ corresponding to $\mathrm{b} / \mathrm{a}=0.8, \mathrm{c}=2$, $\epsilon=-02352$. Here, $y_{i}=1.257$ a, computed from Equation (12), is the maximum ice depth at $z=0$; the minimum ice depth is 0.886 a at $z / y_{i}= \pm 2$ This represents a perturbation between $+25 \%$ to $-11 \%$ on the depth of a uniform channel. The ratio of the half width of the glacier valley to the depth of valley at the

$$
\begin{aligned}
& \tau_{x y}^{a}=\frac{-K\left[\left[\frac{y}{a}\right]^{3}+\frac{3 \epsilon C_{1} y}{a^{4}} \sinh \left[\frac{\sqrt{3 y}}{b} \cos z / b\right]\right.}{\left\{\left[\left[\frac{y}{a}\right]^{3}+\frac{3 \epsilon C_{1}}{a^{4}} y \sinh \left[\sqrt{\frac{3 y}{b}} \cos \frac{z}{b}\right]^{2}+\left[\frac{\epsilon C_{1} b}{a^{4}}\left[\sqrt{\frac{3 y}{b}} \cosh \left[\frac{\sqrt{3 y}}{b}\right]-\sinh \left[\frac{\sqrt{3} y}{b}\right]\right) \sin \frac{z}{b}\right]^{2}\right\}^{1 / 2}\right.} \\
& \tau_{x z}^{a}=\frac{\frac{K \in C_{1} b}{a^{4}}\left[\frac{\sqrt{3} y}{b} \cosh \frac{\sqrt{3} y}{b}-\sinh \frac{\sqrt{3} y}{b}\right] \sin \frac{z}{b}}{\left.\left\{\left[\left[\frac{y}{a}\right]^{3}+\frac{3 \epsilon C_{1}}{a^{4}} y \sinh \left[\frac{\sqrt{3} y}{b}\right] \cos \frac{z}{b}\right]^{2}+\left[\frac{\epsilon C_{1} b}{a^{4}}\left[\sqrt{\frac{3 y}{b}}\right]-\sinh \left[\sqrt{\frac{3 y}{b}}\right]\right]^{\sin \frac{z}{b}}\right]^{2}\right\}^{1 / 2}}
\end{aligned}
$$

This stress field satisfies equilibrium only out to first order $\epsilon$ and differs by order $\epsilon^{2}$ from the original stress field. In terms of the dimensionless variables $Y=y / y_{i}$, $z=z / y_{i}$, the dimensionless associated effective stress becomes thalweg is $w / 2 h=2 / 0.295 \approx 7, a$ value which is well within the range of actual glacier valleys. (Shoemaker (in press) presents $\mathrm{w} / 2 \mathrm{~h}$ values for various glacier and fjord valleys which correspond to the range $1 \leqslant \mathrm{w} / 2 \mathrm{~h}$ $\leqslant 10)$.

$$
\begin{aligned}
& T^{a}=\left\{\left[\left(\frac{\pi b}{c a} Y\right)^{3}+\frac{3 \pi \epsilon C_{1}}{c a^{3}} \frac{b}{a} Y \sinh \left[\sqrt{\frac{3}{n}} \mathrm{Y}\right] \cos \left[\frac{\pi Z}{c}\right]\right]^{2}+\right.
\end{aligned}
$$

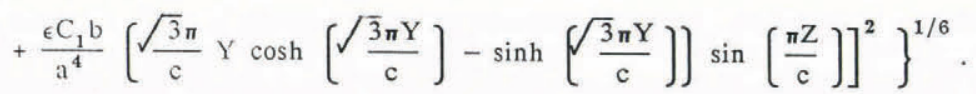

Several numerical examples suggest the following conclusions: (i) $\mathrm{T}$ and $\mathrm{T}^{\mathrm{a}}$ differ uniformly by well less than $|\epsilon|$, (ii) the values of $T^{a} / T$ tend to oscillate slowly about unity, (iii) the relative error $\left|\left(T-T^{a}\right) / T\right|$, for fixed $\mathrm{z} / \mathrm{y}_{\mathrm{i}}$, is minimized at the base and maximized near the free surface, (iv) overall equilibrium is satisfied to at least two figures. This latter conclusion is arrived at by numerical integration of the basal drag. (v) Finally, comparison of $\mathrm{T}$ and $\mathrm{T}^{\mathrm{a}}$ values for several numerical examples supports the conclusion that there is satisfactory domination of the $\epsilon^{2}$ and $\epsilon^{3}$ terms in Equation (17) provided $I \in I$ is small compared to unity.

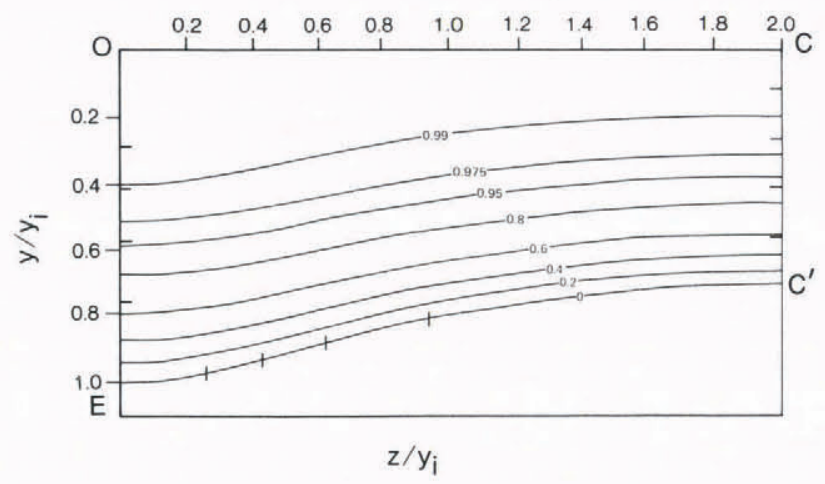

Fig. 6. Dimensionless velocity profiles $U$ and boundary associated effective stresses $T^{a}$ for the case $c=2$ $b / a=0.8, \epsilon=-0.235$. The tick marks indicate equal stress increase over intervals $C C^{\prime}, C^{\prime} E$, and $E O . T^{a}=0$ on $O C$. The key stresses are: $0: T^{a}=0$; $C^{\prime}: T^{a}=1.028 ; E: T^{a}=0.898$.
The Nye shape factor for the example is $f=0.71$. This can be compared to the value $f=0.73$ corresponding to a linear material flowing in profile $F$ of Figure 3, a very similar but slightly deeper profile. Thus, the Nye shape factor is very insensitive to the non-linear flow law. The velocity profiles corresponding to profile $F$ of Figure 3, however, are qualitatively dissimilar to those of Figure 6. Rather, they are similar to Figure 4 in that they intersect the free surface; the dimensionless velocity $U$ varies between 1.23 and 0.769 on the free surface of profile $F$ of Figure 3. Moreover, the velocity gradients corresponding to Figure 6 are much steeper near the base and much less steep near the free surface as compared with the linear case. This result is, of course, consistent with the flow law.

\section{PROFILES FOR $n=3$ INTERSECTING $z$-AXIS}

Nye (1965) presented an analytical solution due to W. Chester for a slightly elliptic channel. A standard perturbation technique was employed. We shall again consider a multi-parameter inverse technique which will involve four independent small parameters. Nye's solution will be obtained by setting three of the parameters, equal to zero. The emphasis will be upon exhibiting a variety of channel shapes for which exact solutions can be obtained corresponding to a zero-velocity basal condition.

The single equilibrium equation in cylindrical coordinates is

$$
\partial \tau_{r X} / \partial r+\frac{1}{r} \partial \tau_{\theta X} / \partial \theta+\tau_{r X} / r=-K / a
$$


We consider the stress field

$$
\begin{gathered}
\tau_{r x}=K\left[-r / 2 a+\sum_{j=1}^{4} \epsilon_{2 j} f_{2 j}\left[\frac{r}{a}\right] \cos (2 j \theta)\right] \\
\tau_{\theta x}=K\left[\sum_{j=1}^{4} \epsilon_{2 j} g_{2 j}\left[\frac{r}{a}\right] \sin (2 j \theta)\right]
\end{gathered}
$$

which reduces to the stress field for flow in a semicircular channel of radius a if $\epsilon_{2 j}=0$. As before, $\mathrm{K}$ is the basal shear stress in a channel of uniform depth a.

The free-surface boundary condition is

$$
\tau_{\theta \mathrm{x}}(\mathrm{r}, \pi / 2)=0
$$

and symmetry implies that

$$
\tau_{\Theta \mathrm{x}}(\mathrm{r}, 0)=0 .
$$

Both boundary conditions are satisfied by Equation (30).

Substitution of Equations (29) and (30) into Equation (28) determines functions $g_{2 j}$ in terms of $f_{2 j}$
such that equilibrium is satisfied. Thus

$$
g_{2 j}=-\frac{r}{2 j}\left[\frac{f_{2 j}^{\prime}}{a}+\frac{f_{2 j}}{r}\right] .
$$

Glen's flow law (2) in cylindrical coordinates is

$$
\frac{\partial \mathrm{u}}{\partial \mathrm{r}}=\mathrm{A} \tau^{\mathrm{n}-1^{1}} \tau_{\mathrm{rX}}, \frac{1}{\mathrm{r}} \frac{\partial \mathrm{u}}{\partial \theta}=\mathrm{A} \tau^{\mathrm{n}-1^{1}} \tau_{\theta \mathrm{X}} .
$$

The stress field given by Equations (29) and (30) along with (33) is substituted into Equation (2'). This results in an expansion in $\epsilon$ out to third powers. Truncating the higher powers enables one to obtain a velocity fieid which is associated with the stress field out to first power of $\epsilon$. Differential equations also result for the determination of $\mathrm{f}_{2 \mathrm{j}}$. These are

$$
\frac{r}{a} f_{2 j}^{\prime \prime}\left[\frac{r}{a}\right)^{\prime}+5 \frac{r}{a} f_{2 j}^{\prime}-3\left[(2 j)^{2}-1\right] f_{2 j}=0
$$

with the regular solutions

$$
\left.f_{2 j}\left(\frac{r}{a}\right)=\left[\frac{r}{a}\right]^{\left[-2+\sqrt{1+3(2 j)^{2}}\right.}\right] .
$$

The resultant velocity field is

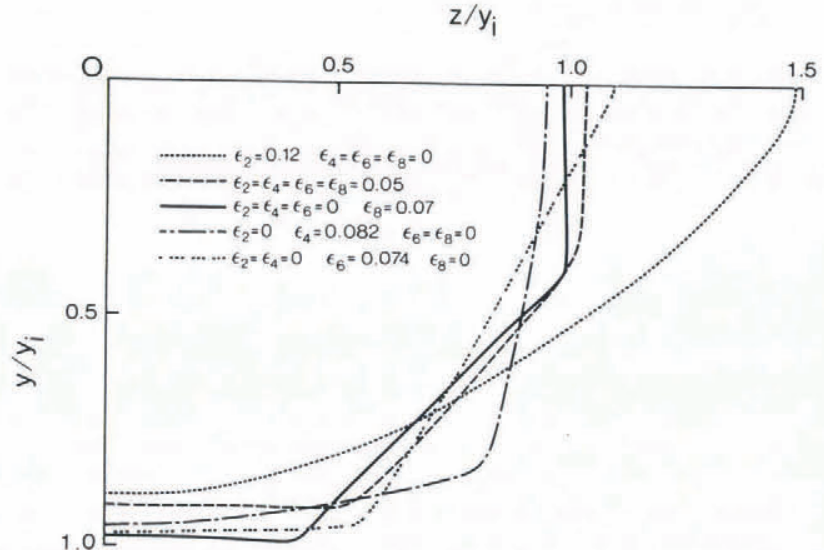

Fig. 7. Five profile perturbations on a semicircular filled channel.

where the constant of integration was determined by the condition that Equation (36), if $\epsilon_{2 j}=0$, reduces to Nye's solution for flow in a semicircular channel. The stress fields will not be investigated here but are easily obtained by substitution of Equation (35) into Equations (29) and (30).

The restriction of "small perturbations" are satisfied if the coefficients in Equation (36), e.g. $\left|\epsilon_{6}\right| 2 / 9\left|\epsilon_{6}\right|$ $(-1+\sqrt{109})$ are small compared with unity. These coefficients $\bar{\epsilon}_{2}, \bar{\epsilon}_{4}, \bar{\epsilon}_{6}$, and $\bar{\epsilon}_{8}$ are the effective small parameters.

To within the accuracy of the perturbation scheme Nye's solution for an elliptic channel is obtained if $\epsilon_{4}=\epsilon_{6}=\epsilon_{8}=0$.

Figure 7 illustrates various basal profiles which satisfy the small parameter restriction. The values of the effective small parameters for the four cases where there is only one non-zero $\epsilon_{2} \mathrm{j}$ are: $\bar{\epsilon}_{2}=0.625$, $\bar{\epsilon}_{4}=0.246, \bar{\epsilon}_{6}=0.155, \bar{\epsilon}_{8}=0.113$. Thus, the solution corresponding to the ellipsetike channel, which is similar to Nye's solution, may violate the small-parameter restriction. Parameter values are acceptably small for the other examples. The effect of $\epsilon_{4}, \epsilon_{6}$, and $\epsilon_{8}$ upon shape may be ascertained by comparison of the profiles. By using even higher-order terms it should be possible to match profiles which are of particular interest. However, it must be noted that all such profiles must satisfy the condition that $|\mathrm{w} 2 / \mathrm{h}-1|$ be small compared to unity. Most glacier valleys fall outside this range.

\section{CONCLUSION}

The inverse technique exhibited here was developed by the author primarily for use in obtaining exact solutions where a sliding law is included, an extension of Shoemaker (in press). In the form exhibited here, the technique is applicable to cold-based glaciers. The flow law, however, is restricted to be homogenous.

$$
\begin{aligned}
u & =\frac{\mathrm{AK}^{3} \mathrm{a}}{32}\left\{1-\left[\frac{\mathrm{r}}{\mathrm{a}}\right]^{4}+\left[\frac{\mathrm{r}}{\mathrm{a}}\right]^{3}\left[2 \epsilon_{2}(-1+\sqrt{13})\left[\frac{\mathrm{r}}{\mathrm{a}}\right]^{-2+\sqrt{13}} \cos 2 \theta+\right.\right. \\
& +3 \epsilon_{4}\left[\frac{\mathrm{r}}{\mathrm{a}}\right]^{5} \cos 4 \theta+\frac{2}{9} \epsilon_{6}(-1+\sqrt{109})\left[\frac{\mathrm{r}}{\mathrm{a}}\right]^{-2}+\sqrt{109} \cos 6 \theta+ \\
& \left.\left.+\frac{1}{8} \epsilon_{8}(-1+\sqrt{193})\left[\frac{\mathrm{r}}{\mathrm{a}}\right]^{-2+\sqrt{193}} \cos 8 \theta\right]\right\}
\end{aligned}
$$




\section{ACKNOWLEDGEMENTS}

The author wishes to thank Vincent $\mathrm{Ng}$ for doing the numerical calculations and the NSERC of Canada for financial support.

\section{REFERENCES}

Bromer, D.J., and Kingery, W.D. 1968. Flow of polycrystalline ice at low stresses and small strains. Journal of Applied Physics, Vol. 39, No. 3, p. 1688-91.

Colbeck, S.C., and Evans, R.J. 1973. A flow law for temperate glacier ice. Journal of Glaciology, Vol. 12, No. 64 , p. $71-86$.

Dorrer, E. 1971. Movement of the Ward Hunt Ice Shelf, Ellesmere Island, N.W.T., Canada. Journal of Glaciology, Vol. 10 , No. 59 , p. $211-25$.

Gerrard, J.A.F., and others. 1952. Measurement of the velocity distribution along a vertical line through a glacier, [by] J.A.F. Gerrard, M.F. Perutz, and A. Roch. Proceedings of the Royal Society of London, Ser. A, Vol. 213 , No. 1115 , p. 546-58.

Jellinek, H.H.G., and Brill, R. 1956. Viscoelastic properties of ice. Journal of Applied Physics, Vol. 27, No. 10, p. 1198-1209.

Landauer, J.K. 1955. Stress-strain relations in snow under uniaxial compression. Journal of Applied Physics, Vol. 26, No. 12, p. 1493-97.

Mellor, M., and Testa, R. 1969. Creep of ice under low stress. Journal of Glaciology, Vol. 8, No. 52, p. 147-52.
Morland, L.W., and Shoemaker, E.M. 1982. Ice shelf balances. Cold Regions Science and Technology, Vol. 5, No. 3 , p. $235-41$.

Nye, J.F. 1953. The flow law of ice from measurements in glacier tunnels, laboratory experiments, and the Jungfraufirn borehole experiment. Proceedings of the Royal Society of London, Ser. A, Vol. 219, No. 1139, p. 477-89.

Nye, J.F. 1957. The distribution of stress and velocity in glaciers and ice-sheets. Proceedings of the Royal Society of London, Ser. A, Vol. 239, No. 1216, p. 113-33.

Nye, J.F. 1965. The flow of a glacier in a channel of rectangular, elliptic, or parabolic cross-section. Journal of Glaciology, Vol. 5, No. 41, p. 661-90.

Paterson, W.S.B. 1981. The physics of glaciers. Second edition. Oxford, etc., Pergamon Press. (Pergamon International Library.)

Shoemaker, E.M. In press. Debris-influenced sliding laws. Journal of Glaciology.

Shreve, R.L., and Sharp, R.P. 1970. Internal deformation and thermal anomalies in lower Blue Glacier, Mount Olympus, Washington, U.S.A. Journal of Glaciology', Vol. 9 , No. 55 , p. $65-86$.

Thomas, R.H. 1971. Flow law for Antarctic ice shelves. Nature, Physical Science, Vol. 232, No. 30, p. 85-87.

Weertman, J. 1957. On the sliding of glaciers. Journal of Glaciology, Vol. 3, No. 21, p. 33-38.

Weertman, J. 1964. The theory of glacier sliding. Journal of Glaciology, Vol. 5, No. 39, p. 287-303.

Weertman, J. 1973. Creep of ice. (In Whalley, E., and others, ed. Physics and chemistry of ice: papers presented at the Symposium on the Physics and Chemistry of Ice, held in Ottawa, Canada, 14-18 August 1972. Edited by E. Whalley, S.J. Jones, L.W. Gold. Ottawa, Royal Society of Canada, p. 320-37.) 